\title{
Battery obsolescence, industry profit and deep brain stimulation
}

\author{
Marwan Hariz $^{1}$
}

Received: 10 August 2019 / Accepted: 14 August 2019/Published online: 23 August 2019

(C) Springer-Verlag GmbH Austria, part of Springer Nature 2019

Deep brain stimulation (DBS) is an evidence-based efficient surgical therapy for advanced Parkinson's disease, dystonia and tremor. It has virtually replaced ablative lesions (thalamotomy, pallidotomy), especially thanks to its safety when applied bilaterally on the motor thalamus, the globus pallidus and the subthalamic nucleus. Also, the "reversibility" of DBS has been a long-advertised feature of this therapy. However, it is evident today that after some time, DBS is no longer "reversible", meaning that patients cannot just stop the stimulation and go back to usual medications. In fact, a sudden arrest of chronic DBS may be dangerous for patients, provoking a rebound of symptoms that may even lead to death, due to medication-refractory malignant Parkinsonian crisis, or dystonic crisis $[3,4,14,15]$. This has led to a new "diagnosis" being proposed: "DBS withdrawal syndrome" $[9,13,14]$. Patients may become "hooked" on DBS and will need regular battery replacements, with financial and clinical consequences such as increased risk for infection at each implantable pulse generator (IPG) replacement $[5,12]$. IPGs with rechargeable batteries are not suitable to many DBS patients due to their reluctance, or to advanced age or difficulty to manage the regular charging of the batteries, or even due to costs.

The dominating DBS hardwares from the 1990s and early 2000s, the Kinetra (for bilateral DBS) and the Soletra (for unilateral DBS), had a reasonable battery life up to 67 years or beyond. However, these were replaced in the mid2000 by a new generation of IPGs called Activa PC (for bilateral DBS) and Activa SC (for unilateral), and these harboured some additional stimulation features, but at the same time appeared to have a shorter battery life than the previous generation.

This article is part of the Topical Collection on Functional NeurosurgeryMovement disorders

Marwan Hariz

Marwan.hariz@umu.se

1 Department of Clinical Neuroscience, Umeå University, 90185 Umeå, Sweden
In this issue of Acta Neurochirurgica, a team from Clermont-Ferrand, France, publishes a paper entitled "Pulse Generator Battery Life in Deep Brain Stimulation: Out with the old... in with the less durable?" [1]. The authors show that the newer generation of Medtronic's DBS IPGs (the dualchannel Activa PC and the single-channel Activa SC) has a much shorter battery life than the older dual-channel Kinetra and single-channel Soletra. This confirms the impression of many workers with large experience in DBS and also corroborates previous published reports from Seoul, Kiel, Berlin, Birmingham, Tel Aviv and Grenoble [2, 6, 7, 10, 11, 16] establishing that the older brands of IPGs "Kinetra" and "Soletra" had a battery lasting up to twice as long as the newer brands Activa PC and Activa SC. The analysis of the data in the present paper from Clermont-Ferrand is very solid, and the authors show that the older batteries lasted twice as long as the newer ones. The authors point to the consequences of this on health costs and on the accumulated risks entailed when frail patients with progressively advanced sickness have to be operated more frequently to change the depleted IPGs.

A recent Editorial in Brain Stimulation [9] speculated that "the decision to eliminate the Kinetra ${ }^{\mathrm{TM}}$ was a marketing decision to generate more profits" and that its replacement with hardware with substantially shorter battery life does "affect patient safety (increased infection risk at subsequent battery changes) and our health care systems."

Is there any sense of "déjà vu, déjà vécu" in this? Yes, indeed:

On 29 December 2018, as reported in "Le Monde" (http:// www.lemonde.fr/entreprises/article/2017/12/29/apple-sexcuse-et-reduit-le-cout-de-remplacement-de-ses-batteries 5235580_1656994.html?xtmc=obsolescence $\&$ xtcr=2:) and on 8 January 2019 as reported by the BBC (http://www.bbc. com/news/technology-42508300), the French government investigated the company Apple for "planned obsolescence" of their iPhone batteries, and the company apologised and promised to reduce the costs of battery replacement of iPhones. On 26 July 2019, The Telegraph in London disclosed that the UK government launched an "inquiry into 
'Tsunami' of e-waste", and one member of Parliament warned that "tech is often designed to become obsolete" (https:/Www. telegraph.co.uk/news/2019/07/26/phones-washing-machinesmust-made-last-mps-say-government-launches/).

Thus, one can speculate that the fact that one major DBS company had cut substantially the longevity of the battery of its IPGs may well fit into this pattern, that is, decreasing the life span of the IPG battery in order to increase profit by selling more IPGs.

The issue is that when this drive to steadily increase profit is applied to iPhones or other electronic hardwares, one may or may not cope or forgive, but when this adamant pursuit of an ever-increasing profit concerns important healthcare products, this becomes a relevant ethical issue: healthcare budgets are depleted ("In some health care systems where there is a fixed budget available for DBS and other neuromodulation devices, this has led to patients being denied therapy in a fiscal year...") [8], and in countries where DBS is not reimbursed by social security, patients' financial situation can be heavily affected and their lives may be put at risk [13]. These aspects need to be discussed more in depth, and, to paraphrase the recent Editorial in the Journal Brain Stimulation [8], "it behooves us to report these issues to our government approval bodies, as part of post-marketing surveillance."

\section{Compliance with ethical standards}

Conflict of interest The author has received from Medtronic, Abbott and Boston Scientific travel expenses and honoraria for speaking at meetings.

\section{References}

1. de Schlichting E, Coll G, Zaldivar-Jolissaint JF, Coste J, Marques AR, Mulliez A, Durif F, Lemaire JJ (2019) Pulse generator battery life in deep brain stimulation: out with the old... in with the less durable. Acta Neurochir (in press)

2. Fisher B, Kausar J, Garratt H, Hodson J, White A, Ughratdar I, Mitchell R (2018) Battery longevity comparison of two commonly available dual channel implantable pulse generators used for subthalamic nucleus stimulation in Parkinson's disease. Stereotact Funct Neurosurg 96:151-156
3. Hariz M (2016) Once STN DBS, always STN DBS? -clinical, ethical, and financial reflections on deep brain stimulation for Parkinson's disease. Mov Disord Clin Pract 3:285-287

4. Hariz MI, Johansson F (2001) Hardware failure in parkinsonian patients with chronic subthalamic nucleus stimulation is a medical emergency. Mov Disord 16:166-168

5. Helmers AK, Lübbing I, Birkenfeld F, Witt K, Synowitz M, Mehdorn HM, Falk D (2018) Complications of impulse generator exchange surgery for deep brain stimulation: a single-center, retrospective study. World Neurosurg. https://doi.org/10.1016/j.wneu. 2018.01.183

6. Helmers AK, Lübbing I, Deuschl G, Witt K, Synowitz M, Mehdorn HM, Falk D (2018) Comparison of the battery life of nonrechargeable generators for deep brain stimulation. Neuromodulation 21:593-596

7. Israeli-Korn SD, Fay-Karmon T, Tessler S, Yahalom G, Benizri S, Strauss H, Zibly Z, Spiegelmann R, Hassin-Baer S (2019) Decreasing battery life in subthalamic deep brain stimulation for Parkinson's disease with repeated replacements: just a matter of energy delivered. Brain Stimul 12:845-850

8. Kiss ZHT, Hariz M (2019) "New and improved" DBS batteries? Brain Stimul 12:833-834

9. Neuneier J, Barbe MT, Dohmen C, Maarouf M, Wirths J, Fink GR, Timmermann L (2013) Malignant deep brain stimulationwithdrawal syndrome in a patient with Parkinson's disease. Mov Disord 28:1640-1641

10. Niemann M, Schneider GH, Kühn A, Vajkoczy P, Faust K (2018) Longevity of implantable pulse generators in bilateral deep brain stimulation for movement disorders. Neuromodulation 21:597-603

11. Park K, Lim YH, Jang M, Kim A, Kim HJ, Paek SH, Jeon B (2018) Battery life matters in deep brain stimulation. Stereotact Funct Neurosurg 96:65-66

12. Pepper J, Zrinzo L, Mirza B, Foltynie T, Limousin P, Hariz M (2013) The risk of hardware infection in deep brain stimulation surgery is greater at impulse generator replacement than at the primary procedure. Stereotact Funct Neurosurg 91:56-65

13. Rajan R, Krishnan S, Kesavapisharady KK, Kishore A (2016) Malignant subthalamic- stimulation withdrawal syndrome in Parkinson's disease. Mov Disord Clin Pract 3:288-291

14. Reuter S, Deuschl G, Falk D, Mehdorn M, Witt K (2015) Uncoupling of dopaminergic and subthalamic stimulation: lifethreatening DBS withdrawal syndrome. Mov Disord 30:14071413

15. Rohani M, Munhoz RP, Shahidi G, Parvaresh M, Miri S (2017) Fatal status dystonicus in tardive dystonia due to depletion of deep brain stimulation's pulse generator. Brain Stimul 10:160-161

16. Sette AL, Seigneuret E, Reymond F, Chabardes S, Castrioto A, Boussat B, Moro E, François P, Fraix V (2019) Battery longevity of neurostimulators in Parkinson disease: a historic cohort study. Brain Stimul 12:851-857

Publisher's note Springer Nature remains neutral with regard to jurisdictional claims in published maps and institutional affiliations. 